\title{
Chronic obstructive pulmonary disease with lung cancer: Prevalence, severity, and common pathogenesis
}

\author{
John P. Griffin ${ }^{1, *}$, Elizabeth A. Tolley², Muhammad K. Zaman ${ }^{3}$, Harvey B. Niell ${ }^{4}$, F. Hammond Cole Jr. ${ }^{5}$ and Darryl S. Weiman ${ }^{6}$ \\ ${ }_{1}^{1}$ Pulmonary Medicine and Preventive Medicine, University of Tennessee Health Science Center, Memphis, TN 38163, USA \\ 2 Department of Preventive Medicine, University of Tennessee Health Science Center, Memphis, TN 38163, USA \\ ${ }^{3}$ Pulmonary and Critical Care Medicine Section, Memphis Veterans Affairs Medical Center, Memphis, TN 38104, USA \\ ${ }^{4}$ Hematology and Oncology Division, University of Tennessee Health Science Center, Memphis, TN 38163, USA \\ ${ }^{5}$ Thoracic Surgery Section, University of Tennessee Health Science Center, Memphis, TN 38163, USA \\ ${ }^{6}$ Surgery Service, Memphis Veterans Affairs Medical Center, Memphis, TN 38104, USA
}

\begin{abstract}
Objectives: To develop a clinical prediction model of contribution of chronic obstructive pulmonary disease (COPD) to the pathogenesis of lung cancer, by reporting the estimated prevalence and severity by GOLD criteria in a single-institution cohort of patients with newly diagnosed lung cancer. Primary objective was investigating the effects of impaired lung function with various histological cell types on crude survival, while considering the initial staging of disease extent. Materials \& methods: A total of 441 patients, in this historical cohort from electronic medical records, completed spirometry prior to invasive diagnostic procedures and initial treatment of their lung cancer. All statistical analyses, including ANOVA and survival analysis, were performed using SAS version 9.1 software. Results: Estimated prevalence of COPD was $79.1 \%$ (95\% confidence interval: $71.3 \%-82.9 \%)$. Lung function as measured by spirometry was a significant predictor of survival time in months $(p<.0001)$ both with and without adjusting for tumor-cell-type, age, and stage of disease. Median survival was similar $(p=0.32)$ and longer among those patients with normal pulmonary function, those with restrictive disease patterns, and those with COPD-GOLD-1 defects. Median survival was shortest among patients with COPD-GOLD-4 impairment $(p=0.001)$. Those patients with COPD-GOLD-2 and COPD-GOLD-3 impairment levels had intermediate survival times $(p=0.003)$. Conclusions: This investigation suggests that strategies for early detection and slowing the progression of COPD before the development of lung cancer might increase patient survival. As demonstrated in this study, the presence and severity of COPD in lung cancer patients is an independent predictor of survival time, different from the established staging of initial extent of disease.
\end{abstract}

Keywords: COPD; pulmonary disease; lung cancer; prevalence; common pathogenesis

\section{Introduction}

Chronic obstructive pulmonary disease (COPD) and bronchogenic carcinoma have long been considered distinct lung diseases, with commonly a similar etiology from cigarette smoking. Clinical physiologists have been seriously preoccupied with the prediction of the possible tolerable extent of "curative" resection in patients with lung cancer and coexistent major compromise of pulmonary function. The NHLBI/WHO Global Initiative for Chronic Obstructive Pulmonary Disease (GOLD) provided an international strategy for grading the severity of COPD for diagnosis, management, and prevention.

Thomas Petty, a clinical scholar in COPD teaching, asked the question: "are COPD and lung cancer two manifestations of the same disease" [1]? This might be genetically determined by creating a predisposition for environmental and personal insults that permit clinical expression of both disorders. The $1^{\text {st }}$ National Health and Nutrition Examination Survey after $>20$ year follow up of a $>5000$ adult cohort found that obstructive lung disease was associated with increased risk of incident lung cancer [2]. Smoking, air pollution and occupational toxins might cause an accumulation of damaging mutations that inflame and destroy alveoli, while also inducing dysplastic and even neoplastic changes. The $54^{\text {th }}$ Aspen Lung Conference in 2012 was devoted to investigation of the "common pathogenesis and shared clinical challenges of chronic obstructive pulmonary disease and lung cancer" [3].

*Corresponding author: John P. Griffin, MD, FACP, FCCP, Professor of Pulmonary and Preventive Medicine; University of Tennessee Health Science Center; 956 Court Avenue, Room G-228; Memphis, TN 38163, USA. Tel.: (901) 448-5757; Fax (901) 448-7726; Email: jpgriffin@uthsc.edu

Received 28 October 2015 Accepted 4 December 2015 Published 11 December 2015

Citation: Griffin JP, Tolley EA, Zaman MK, Niell HB, Cole FH Jr, Weiman DS. Chronic obstructive pulmonary disease with lung cancer: Prevalence, severity, and common pathogenesis. J Cancer Res Ther. 2016; 4(1):1-6. DOI:10.14312/2052-4994.2016-1

Copyright: (c) 2016 Griffin JP, et al. Published by NobleResearch Publishers. This is an open-access article distributed under the terms of the Creative Commons Attribution License, which permits unrestricted use, distribution and reproduction in any medium, provided the original author and source are credited. 
The association between COPD and lung cancer has been demonstrated in epidemiological population-based, case control, prevalence, and incidence studies, as well as in lung cancer screening programs. This investigation reports on the prevalence of COPD and gradations of severity by GOLD criteria in a large well-studied single institution observational cohort of newly diagnosed patients with lung cancer, previously reported with respect to bronchoscopic techniques [4]. The primary objective was investigating the effects of impaired pulmonary function at diagnosis on survival in the context of potential confounders or effect modifiers, including age, histological lung cancer type, and initial staging extent of disease.

\section{Methods}

From 1988-2001, a single team of pulmonologists was responsible for the diagnosis, staging, and recommendation for initial treatment, of all patients with newly diagnosed lung cancer at the Memphis Veterans Affairs Medical Center. Allowing for small variations in treatment protocols over this time period, the uniqueness of this particular cohort is the continuity of care attributable to the practice guidelines adhered to by this single pulmonary team with $98 \%$ patient follow up to 10 years.

A total of 456 patients in this historical cohort with pulmonary function studies performed, prior to invasive diagnostic procedures and initial treatment for their lung cancer, were identified from electronic medical records. Of these, 15 were excluded due to surgical deaths, occurring within 30 days of resection, leaving a total of 441 patients. Spirometric results were specifically examined by GOLD criteria to identify the prevalence and severity of COPD [5, 6] (Table 1). Also, the prevalence of presumptive restrictive ventilatory defects, and of studies within normal limits, was recorded.

Table 1 Definition of spirometry subgroups.

\begin{tabular}{lll}
\hline FEV1/FVC ratio & FEV1 & Lung function group \\
\hline$<0.70$ & $>80 \%$ predicted & GOLD I obstruction \\
$<0.70$ & $>50 \%<80 \%$ predicted & GOLD II obstruction \\
$<0.70$ & $>30 \%<50 \%$ predicted & GOLD III obstruction \\
$<0.70$ & $<30 \%$ predicted & GOLD IV obstruction \\
$>0.70$ & FVC $<80 \%$ predicted & presumptive restriction \\
$>0.70$ & FVC $>80 \%$ predicted & within normal limits \\
\hline
\end{tabular}

Diagnoses of specific tumor cell types were classified by cytologic/ histologic criteria as follows: 1. squamous cell carcinomas, of all stages of differentiation, 2 . adenocarcinomas, including bronchioloalveolar, and adenosquamous types, 3. neuroendocrine carcinomas, including small cell, large cell, and atypical carcinoid types, 4. non-small cell lung cancer (NSCLC), including giant cell, and poorly differentiated large cell types. Stages of extent of lung cancer were recorded as I, II, III, or IV.

\section{Statistical considerations}

Groups with pulmonary function studies were compared using t-tests, chi-square tests and two-way ANOVA. Mean ages of the six pulmonary function subgroups and of the tumor-cell-type categories were analyzed with one-way ANOVAs with a preplanned contrast comparing those with and without COPD. Goodness of fit tests were used to determine whether lung-function and tumor-cell-type categories were independent. Overall survival was defined as the time from diagnosis to date of death for those who died and to date of last follow up for those who were still alive at last follow up, and these patients were censored in their last follow up date. The PHREG procedure was used to investigate the association of factors of interest with overall survival, where the Kaplan-Meier method was used to estimate the survival distribution for levels of factors of interest. Initial models considered lung function categories, tumor cell types, and staging of lung cancer in separate analyses univariably without covariates. Then, a multivariable model was constructed to include modified lung function categories, tumor cell types, age at diagnosis in years, and stage of cancer; however, when the various tumor cell types were no longer significant covariates, after adjusting for other variables in the model, tumor cell types were excluded from the final multivariable model to avoid over parameterization. Data from a total of seven patients could not be included in the full model due to lack of pretreatment staging of their disease. All statistical analyses were performed using SAS ${ }^{\circledR}$ version 9.3 software. An alpha of 0.05 was considered as the threshold for statistical significance, all tests and confidence intervals were two-sided and not adjusted for multiplicity.

\section{Results}

A total of 441 patients were included in this study, with $79.1 \%$ (95\% confidence interval: $71.3 \%-82.9 \%$ ) showing spirometric evidence of obstructive ventilatory impairment COPD. Patient characteristics are depicted in Table 2. Only two patients were alive at the time of analysis with survival times of 174 and 176 months; at diagnosis these two survivors were 46 and $58 \mathrm{yrs}$. of age and had COPD (GOLD $=3$ and $G O L D=1$ ), respectively. The cohort was divided into three groups based on results of pulmonary function tests: within normal limits (Normal), restrictive lung disease (Restrictive), and chronic obstructive pulmonary disease (COPD). In addition, the COPD group was subdivided according to the GOLD criteria. Patients without COPD $(n=92)$ were on average significantly younger than those with COPD $(n=349)(64.3 \pm 1.0$ versus $67.9 \pm 0.4, p=0.002)$. Cancer cell types were determined by cytology/histology and grouped into four general classifications.

Age at diagnosis had similar distributions among the different cell types $(p=0.20)$. Lung function and cancer cytology/histology were associated (Table 2; $p=0.03$ ) in that among the patients whose lung function indicated mild impairment (i.e., COPD-GOLD-1), significantly more adenocarcinomas $(p=0.02)$ and fewer squamous cell tumors occurred $(p=0.03)$ than expected.

Tumor cell types alone were associated with time to death in that the hazard of death for those with neuroendocrine cell tumors was higher compared with those with squamous cell tumors (hazard ratio: 1.397; 95\% confidence interval: 1.033-1.890; $p=0.03$ ). Age at diagnosis in years was associated with overall survival (hazard ratio: 1.012; 95\% confidence interval: 1.000-1.023; $p=0.05$ ). 
Table 2 Characteristics of 441 patients included in the cohort.

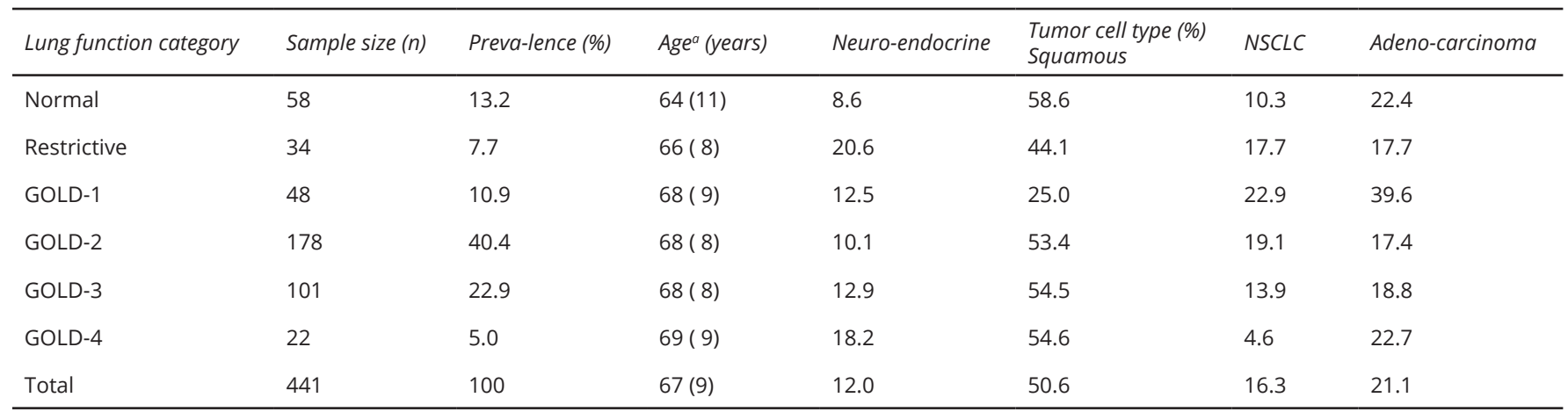

Abbreviations: a Age at diagnosis; mean (standard deviation).

Not unexpectedly, initial stages of the extent of disease, representing levels of one of the most important and clinically relevant diagnostic variables, were significantly predictive of overall survival $(p<0.0001)$ (Table 3, Figure 1).
Because median survival times were similar for patients with Stage I and Stage II disease, these groups were combined to estimate unadjusted hazard ratios.

Table 3 Median survival in months from diagnosis and estimated unadjusted hazard ratios and 95\% confidence intervals relative to those with Stage 1 or Stage II lung cancer.

\begin{tabular}{lcccc}
\hline $\begin{array}{l}\text { Stage extent of } \\
\text { disease }\end{array}$ & Sample size, $n^{a}$ & $\begin{array}{c}\text { Median survival time } \\
\text { (months) }\end{array}$ & $\begin{array}{c}\text { 95\% confidence } \\
\text { interval }\end{array}$ & $\begin{array}{c}\text { Estimated } \\
\text { unadjusted hazard } \\
\text { ratio }\end{array}$ \\
\hline Stage I & 107 & 20.0 & $16.5-24.0$ & $\begin{array}{c}95 \% \text { confidence } \\
\text { interval }\end{array}$ \\
Stage II & 43 & 19.5 & $11.0-29.5$ & Reference category \\
Stage III & 175 & 8.5 & $7.0-10.5$ & 2.250 \\
Stage IV & 108 & 4.75 & $3.0-6.0$ & 3.835 \\
\hline
\end{tabular}

Abbreviations: a Staging was not available for eight patients; ${ }^{b}$ Stage I and Stage II groups were combined.

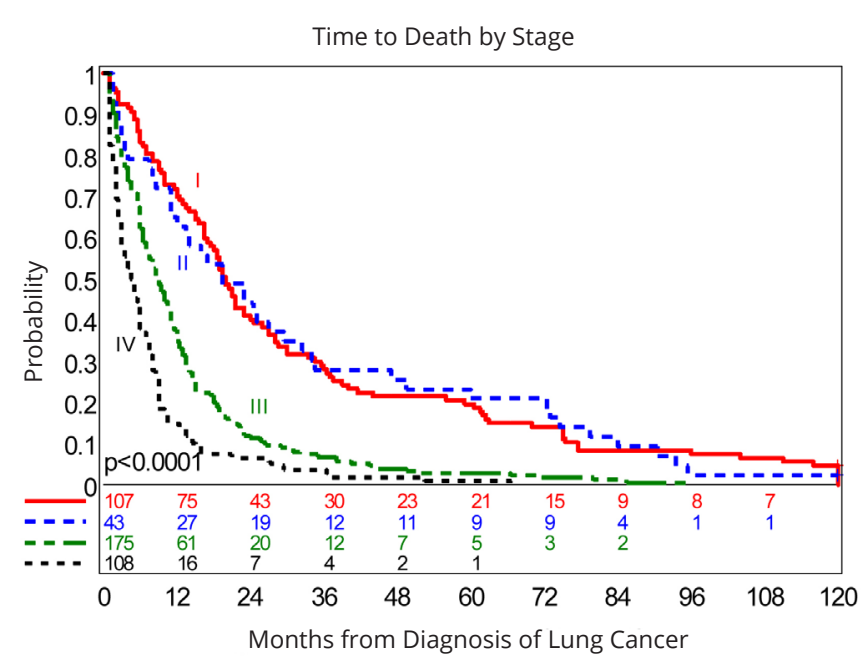

Figure 1 Survival distributions of patients grouped according to stage of extent of disease at time of diagnosis of lung cancer.

Abbreviations: Stage I: $\mathrm{n}=107$; Stage II: $\mathrm{n}=43$; Stage III: $\mathrm{N}=175$; Stage IV: $\mathrm{n}=108$.

Lung impairment as measured by pulmonary function tests was significantly associated with overall survival $(p<0.0001)$ (Table 4). Among those with normal lung function, restrictive lung disease, and COPD-GOLD-1 impairment, median survival was similar $(p=0.32)$, and overall higher than the median survival for those with COPD-GOLD-2 through COPD-GOLD-4 impairment; therefore, these three groups were combined. Considering that those with COPD-GOLD-2 and COPD-GOLD-3 impairment levels had similar median survival $(p=0.09)$, which was higher compared to that of COPD-GOLD-4 impairment $(p=0.03)$, these two categories were combined into one for comparisons against those with normal lung function, restrictive lung disease, and COPD-GOLD-1 impairment, or those with COPD-GOLD-4 impairment, resulting in only three distinct categories to estimate adjusted hazard ratios in subsequent analyses (Table 5). The unadjusted hazard ratios were similar in magnitude to adjusted hazard ratios and are not reported.

In the final multivariable model, moderate (GOLD-2 or GOLD-3) and severe (GOLD-4) lung showed significantly higher hazard of death compared to those with those with normal lung function, restrictive lung disease, or COPDGOLD-1 impairment, controlling for stage of disease extent, and age in years (Table 5; Figure 2). Both stage (as a classification variable) and age in years (as a continuous variable) were highly significant. The adjusted hazard ratios for stages were similar to the respective unadjusted hazard ratios (Table 3 and Table 4). In contrast, during model development the various tumor cell types were no longer significant covariates ( $p$-values ranging from $0.70-0.92$ ), after adjusting for stage, age, and lung function category, and were excluded from the final multivariable model. Importantly, no significant interactions were detected among lung function categories, stage, age, and tumor cell types. Thus, based on this cohort, lung impairment due to COPD and initial stages of the extent of disease, adjusted for age, appear to be independent predictors of overall survival. The implication of these findings is that those patients with severe lung impairment are over 
Table 4 Median survival in months from diagnosis and estimated unadjusted hazard ratios and 95\% confidence intervals relative to those with normal lung function tests.

\begin{tabular}{|c|c|c|c|c|c|c|}
\hline $\begin{array}{l}\text { Lung function } \\
\text { category }\end{array}$ & Sample size, $n$ & $\begin{array}{l}\text { Median survival time } \\
\text { (months) }\end{array}$ & $\begin{array}{l}\text { 95\% confidence } \\
\text { interval }\end{array}$ & $\begin{array}{l}\text { Estimated } \\
\text { unadjusted hazard } \\
\text { ratio }\end{array}$ & $\begin{array}{l}\text { 95\% confidence } \\
\text { interval }\end{array}$ & $P$-value \\
\hline Normal & 58 & 11.50 & $9.0-21.0$ & \multicolumn{2}{|c|}{ Reference category } & \\
\hline Restrictive & 34 & 12.25 & $7.5-17.0$ & 1.185 & $0.775-1.813$ & 0.44 \\
\hline GOLD-1 & 48 & 14.75 & $10.0-24.0$ & 0.856 & $0.582-1.259$ & 0.43 \\
\hline GOLD-2 & 178 & 8.50 & $7.0-10.5$ & 1.290 & $0.958-1.736$ & 0.09 \\
\hline GOLD-3 & 101 & 7.50 & $6.0-9.0$ & 1.629 & $1.176-2.257$ & 0.003 \\
\hline GOLD-4 & 22 & 5.25 & $2.5-11.5$ & 2.347 & $1.427-3.858$ & 0.001 \\
\hline
\end{tabular}

Table 5 Estimated adjusted hazard ratios and 95\% confidence intervals relative to those with normal lung function tests or restrictive disease or COPD-GOLD-1 impairment and/or Stage I or Stage II extent of disease at time of diagnosis.

\begin{tabular}{lccc}
\hline \multicolumn{1}{c}{ Variable } & $\begin{array}{c}\text { Adjusted } \\
\text { hazard ratio }\end{array}$ & $\begin{array}{c}95 \% \text { confidence } \\
\text { interval }\end{array}$ & P-value \\
\hline Stage III & 2.249 & $1.783-2.837$ & $<0.0001$ \\
Stage IV & 4.157 & $3.173-5.448$ & $<0.0001$ \\
$\begin{array}{l}\text { COPD-GOLD-2 or } \\
\text { COPD-GOLD-3 }\end{array}$ & 1.453 & $1.177-1.794$ & 0.0005 \\
COPD-GOLD-4 & 2.756 & $1.738-4.371$ & $<0.0001$ \\
Age in years & 1.012 & $1.001-1.024$ & 0.0371 \\
\hline
\end{tabular}

represented among the early deaths irrespective of the initial stage of the extent of disease; likewise, irrespective of staging those with none to mild lung impairment are over represented among the patients with longer survival times. Finally those with moderate lung impairment tend to have survival times in the mid range across all stages of disease.

Time to Death by Pulmonary Function Group

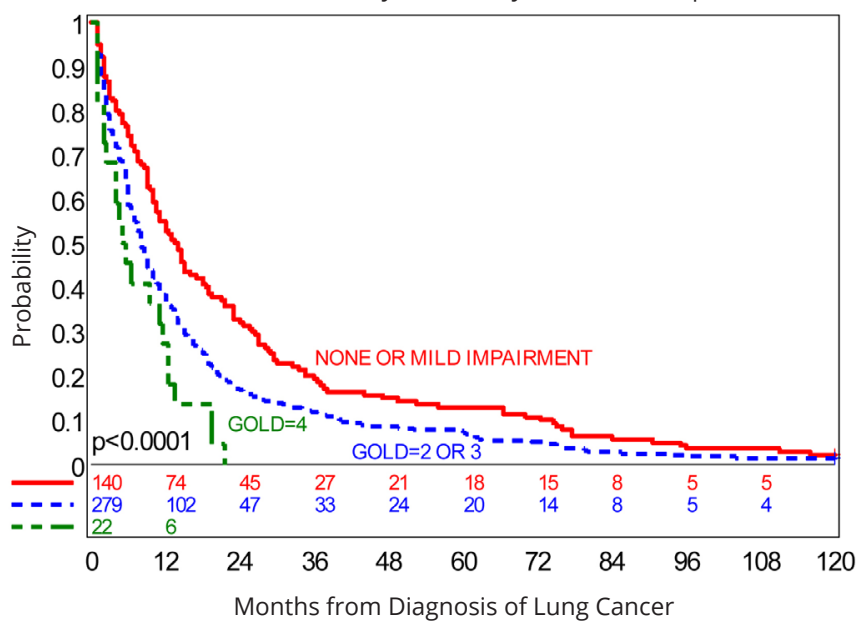

Figure 2 Survival distributions of patients grouped according to results of pulmonary function tests at time of diagnosis of lung cancer.

Abbreviations: Lung Function Group 1 "None or Mild Impairment": Normal lung function, $n=58$, Restrictive pulmonary function, $n=34$, and COPDGOLD-1, n=48; Lung Function Group 2: COPD-GOLD-2, n=178 and COPDGOLD-3, n=101; Lung Function Group 3: COPD-GOLD-4, n=22.

\section{Discussion}

The current study demonstrates that increasing obstructive lung impairment as assessed by spirometry is negatively associated with survival time. In this cohort this effect remained significant after adjusting for age, stage extent of disease, and tumor type. Tumor type alone was also associated with time to death, but after controlling for pulmonary function data was no longer a significant predictor. Logic suggests that increasingly impaired pulmonary function would be a significant contributing factor to reducing survival time following the initial diagnosis of lung cancer. However, until the GOLD guidelines were established, there were no internationally agreed-upon standards for determining the severity of COPD. Using the GOLD definitions, as well as parameters of restrictive impairment and normal pulmonary function, the large impact of diminishing lung function is evident based on this cohort of 441 consecutive lung cancer patients with spirometric findings. Median survival times of patients with GOLD-3 and GOLD-4 COPD were not contained within the $95 \%$ confidence intervals of those patients with normal lung function, apparent restrictive impairment, or GOLD-1 COPD. This finding suggests that strategies to slow the progression of COPD before the development of a patient's lung cancer might be beneficial. This conclusion is supported by the literature, which shows that the presence of COPD in patients with newly diagnosed lung cancer is usually the norm. Most previous studies found that COPD was a risk factor for the development of lung cancer. However, an alternative interpretation is that the two diseases often coexist in the same patients and independently contribute to a common pathogenesis, thereby affecting the survival time of newly diagnosed lung cancer patients.

In 1975 Caplin et al. observed 233 men with defined chronic bronchitis for development of lung cancer, concluding that severe airway obstruction and lung cancer do not often occur together [7]. However in 1986, in a prospective matched control study followed over 10 years, Skillrud et al. found evidence that airflow obstruction is a risk factor for lung cancer [8]. This conclusion was confirmed the following year by Tockman et al. with data suggesting that smokers with ventilatory obstruction were at greater risk for development of lung cancer than smokers without airway obstruction [9]. Bolliger et al. estimated in 2005 that $90 \%$ of patients with lung cancer have underlying COPD and cardiovascular disorders caused by the shared risk factor from tobacco smoking, thus lung resection in those patients is a procedure associated with a higher risk of perioperative complications [10-14]. In the current cohort the prevalence of COPD was 79.6\% (95\% confidence interval: $75.9 \%-83.3 \%)$. 
Bechtel et al. used a questionnaire to prospectively study over a 5 year period, 430 high risk patients in communitybased primary care, with 126 showing airway obstruction developing lung cancer in 8 , but 10 patients without airway obstruction also developed lung cancer [15, 16]. Turner and colleagues found an association between self-reported physician-diagnosed chronic bronchitis and emphysema and lung cancer mortality in a prospective study of 448,600 lifelong nonsmokers, yielding 1,759 lung cancer deaths over a 20 year follow up [17]. Other investigators have considered that the coexisting disease of COPD in an estimated $40-70 \%$ of patients with lung cancer, likely reflects a common smoking exposure [18], and others have noted that the prevalence of at least moderately severe COPD in newly diagnosed lung cancer being 6-fold greater in matched smokers, suggests that COPD itself is an important risk factor in the pathogenesis of lung cancer [19].

In a randomly selected general population of $\sim 14,000$ in Copenhagen the relation of ventilatory function to lung cancer was observed over a 10 year follow up. Lung cancer death occurred in 225 patients, with a 3.9 times higher risk in those with FEV1 $<40 \%$ of predicted [20]. Nomura et al. in a community cohort of 6317 men followed for 22 years had observed 172 incident cases of lung cancer, and noted that $\%$ of FEV1 was inversely related to the development of lung cancer [21]. In the United Kingdom a 15 year prospective general population study of all cause-mortality found significant trends of increasing risk with diminishing FEV1 apparent for all causes of death, with relative hazard ratios for lung cancer of 2.53 for men and 4.37 for women [22]. Kishi et al. used a matched case-controlled study for age, sex, and smoking history to determine if airway obstruction or emphysema were associated with an increased risk of lung cancer. Findings included greatly increased likelihood of developing lung cancer in those with FEV1 $40 \%$ or less of predicted, but CT measurements of emphysema were not associated with increased risk for lung cancer [23]. However, Wilson et al. utilized data from CT screening for lung cancer to relate spirometric airflow obstruction to radiographic emphysema. Of 99 patients developing lung cancer, after adjustment for age, sex, and smoking, logistic regression showed odds ratio 2.09 for GOLD I-IV airflow obstruction, and odds ratio 3.56 for radiographic emphysema [24]. The attached editorial concluded that airflow obstruction, emphysema, and lung cancer should now be considered "partners" [25]. In 2011 deTorres and colleagues reported on a cohort of 2,507 COPD patients in pulmonary clinics, without clinical or radiographic evidence of lung cancer, of whom 215 developed it with a median of 60 months, and incidence density of 16.7 cases/1,000 person-years [26].

Kuller et al. in the Multiple Risk Factor Trial found in a 10 year follow up that in men smokers baseline FEV1 was a powerful predictor of lung cancer death, with rates as high as 3.02/1000 person- years in the lowest quintile of forced expiratory volume [27]. In the Kaiser Permanente Medical Care Program Van den Eeden et al. observed that FEV1 was inversely related to risk of lung cancer among former and current smokers, but not related in neversmokers, concluding that FEV1 appears associated with lung cancer as a physiologic marker for smoking-induced pulmonary damage [28]. Divot et al. have now identified 79 comorbidities in a prospective cohort of 1664 COPD patients in a median 51 months. They calculated survival risk by cox proportional hazard, and developed a specific test (COTE) by multivariate analysis of morbidities contributing to mortality, adding information to the validated BODE index; lung cancer had a 9.1\% prevalence, and hazard ratio 2.02 at $95 \% \mathrm{Cl}[30]$.

In 2006, Brody and Spira noted that both lung cancer and COPD are associated with smoking, which generates reactive oxidant species. Subsequently activation and expression of a number of genes are altered, and a chronic inflammatory state in the lung is induced. DNA damage and lack of repair with genomic instability predominate in lung cancer. In COPD, matrix degeneration with lack of repair, and intense immune responses predominate. Odds ratio for developing lung cancer increases from 1.4 to 4.9 fold with moderate to severe COPD. Expression of putative oncogenes and tumor suppressor genes remains altered for decades after stopping smoking, in patients developing lung cancer. Lung inflammation initiated by reactive oxidant species in cigarette smoke in COPD patients, persists after stopping smoking, explaining progression of the disease [31].

In 2012, Celli summarized the proceedings of the Aspen Lung Conference on the common pathogenesis and shared clinical challenges of COPD and lung cancer. He stated that a common pathogenesis of these two diseases was suggested by their association in population-based studies, lung cancer screening programs, epidemiological surveys, case control, and biological mechanistic studies. Why COPD develops in some patients and lung cancer in others when exposed to similar environmental challenges remains unresolved. What will develop in individual patients will apparently reflect a balance between inflammation and its resolution, a capacity to repair injured tissue, and longterm changes in immunological response or senescence. It was advised that future research efforts should study COPD and lung cancer as different clinical expressions of diseases with many common roots [3].

Our study has limitations. Analyses were performed retrospectively, although all data were collected prospectively. This single institution study in a VA hospitalbased predominant male cohort may not reflect experience with the relationship of COPD, prevalence and severity, and lung cancer in other populations. Frequently endobronchial tumor growth may produce sufficient blockage to manifest a restrictive impairment, also supporting the hypothesis of a common pathogenesis of lung cancer and COPD. Presurgical evaluation was conducted in many patients in this cohort, by a stair-climbing technique, developed by one of our authors (DSW), and shown to predict pulmonary function adequate for lobectomy or pneumonectomy.

Strengths of our investigation include a well-studied inclusive cohort of lung cancer patients from a single laboratory, and with follow up survival data in $98 \%$ of patients by electronic records. We utilized the wellvalidated GOLD criteria for measurement of prevalence 
and severity of COPD by spirometry, prior to initiation of definitive treatment for their lung cancer. We included the initial stage distribution of disease extent in these patients, and analyzed the combined influence of prevalence and severity of COPD, and stage of disease, on survival. Also, we present an inclusive review of the published epidemiological approaches to identifying a "common pathogenesis" of lung cancer and COPD.

\section{Conclusions}

We concluded that increasing obstructive lung impairment, as assessed by spirometry, was negatively associated with survival time in patients newly diagnosed with lung cancer. In this cohort, this effect remained significant after adjusting for age, tumor type, and stage of disease. Petty's question of "are COPD and lung cancer two manifestations of the same disease" [1], is still unresolved. However, many new advances technologically now being applied to this question, as recently reported from the 2012 Aspen Lung Conference [3], promise a better understanding of these usually preventable diseases.

\section{Conflicts interest}

Authors declare no conflicts of interest.

\section{References}

[1] Petty TL. Are COPD and lung cancer two manifestations of the same disease? Chest. 2005; 128(4):1895-1897.

[2] Mannino DM, Aguayo SM, Petty TL, Redd SC. Low lung function and incident lung cancer in the United States: data from the First National Health and Nutrition Examination survey follow-up. Archiv Intern Med. 2003; 163(12):1475-1480.

[3] Celli BR. Chronic obstructive pulmonary disease and lung cancer: common pathogenesis, shared clinical challenges. Proc Am Thorac Soc 2012; 9(2):74-79.

[4] Griffin JP, Zaman MK, Niell HB, Tolley EA, Cole FH, et al. Diagnosis of lung cancer: a bronchoscopist's perspective. J Bronchol Intervent Pulmonol 2012; 19(1):12-18.

[5] Pauwels RA, Buist AS, Calverley PM, Jenkins CR, Hurd SS, et al. Global strategy for the diagnosis, management, and prevention of chronic obstructive pulmonary disease. NHLBI/WHO global initiative for chronic obstructive pulmonary disease (GOLD): workshop summary. Am J Respir Crit Care Med. 2001; 163(5):1256-1276.

[6] Gross NJ. The GOLD standard for chronic obstructive pulmonary disease. Am J Respir Crit Care Med. 2001; 163(5):1047-1048.

[7] Caplin M, Festenstein F. Relation between lung cancer, chronic bronchitis, and airways obstruction. Br Med J. 1975; 3(5985):678-680.

[8] Skillrud DM, Offord KP, Miller RD. Higher risk of lung cancer in chronic obstructive pulmonary disease. A prospective, matched, controlled study. Ann Intern Med. 1986; 105(4):503-507.

[9] Tockman MS, Anthonisen NR, Wright EC, Donithan MG. Airways obstruction and the risk for lung cancer. Ann Intern Med. 1987; 106(4):512-518.

[10] Bolliger CT, Koegelenberg CF, Kendal R. Preoperative assessment for lung cancer surgery. Curr Opin Pulm Med. 2005; 11(4):301-306.

[11] Colice GL, Shafazand S, Griffin JP, Keenan R, Bolliger CT. The physiological evaluation of patients with lung cancer being evaluated for resectional surgery. Chest. 2007; 132(3 suppl):161S-177.

[12] Von Groote-Bidlingmaier F, Koegelenberg CF, Bolliger CT. Functional evaluation before lung resection. Clin Chest Med. 2011; 32(4):773782.

[13] Pate P, Tenholder MF, Griffin JP, Eastridge CE, Weiman DS. Preoperative assessment of the high-risk patient for lung resection. Ann Thorac Surg. 1996; 61(5):494-500.

[14] Griffin JP, Eastridge CE, Tolley EA, Pate JW. Wedge resection for nonsmall-cell lung cancer in patients with pulmonary insufficiency: prospective ten year survival. J Thorac Oncol. 2006; 1(9):960-964.

[15] Bechtel J], Kelley WA, Coons TA, Klein MG, Slagel DD, et al. Lung cancer detection in patients with airflow obstruction identified in a primary care outpatient practice. Chest. 2005; 127(4):1140-1145.
[16] Bechtel لر, Kelley WA, Coons TA, Mohler P, Mohler A, et al. Five-year outcome of lung cancer detection in patients with and without airflow obstruction in a primary care outpatient practice. J Thorac Oncol. 2009; 4(11):1347-1351.

[17] Turner MC, Chen Y, Krewski D, Calle EE, Thun MJ. Chronic obstructive pulmonary disease is associated with lung cancer mortality in a prospective study of never smokers. Am J Respir Crit Care Med. 2007; 176(3):285-290

[18] Dela Cruz CS, Tanoue LT, Matthay RA. Lung cancer: epidemiology, etiology, and prevention. Clin Chest Med. 2011; 32(4):605-644.

[19] Young RP, Hopkins RJ, Christmas T, Black PN, Metcalf $P$, et al. COPD prevalence is increased in lung cancer, independent of age, sex, and smoking history. Eur Respir J. 2009; 34(2):380-386.

[20] Lange P, Nyboe J, Appleyard M, Jensen G, Schnohr P. Ventilatory function and chronic mucus hypersecretion as predictors of death from lung cancer. Am Rev Respir Dis. 1990; 141(3):613-617.

[21] Nomura A, Stemmermann GN, Chyou PH, Marcus EB, Buist AS Prospective study of pulmonary function and lung cancer. Am Rev Respir Dis. 1991; 144(2):307-311.

[22] Hole DJ, Watt GC, Davey-Smith G, Hart CL, Gillis CR, et al. Impaired lung function and mortality risk in men and women: findings from the Renfrew and Paisley prospective population study. BMJ. 1996; 313(7059):711-715.

[23] Kishi K, Gurney JW, Schroeder DR, Scanlon PD, Swensen SJ, et al. The correlation of emphysema or airway obstruction with the risk of lung cancer: a matched case-controlled study. Eur Respir J. 2002; 19(6):1093-1098.

[24] Wilson DO, Weissfeld JL, Balkan A, Schragin CR, et al. Association of radiographic emphysema and airflow obstruction with lung cancer. Am J Respir Crit Care Med. 2008; 178(7):738-744.

[25] Dubinett SM, Aberle DR, Tashkin DP, Mao JT. The partners--airflow obstruction, emphysema, and lung cancer. Am J Respir Crit Care Med. 2008; 178(7):665-666.

[26] De Torres JP, Marin JM, Casanova C, Cote C, Carizzo S, et al. Lung cancer in patients with chronic obstructive pulmonary disease: incidence and predicting factors. Am J Respir Crit Care Med. 2011; 184(8):913-919.

[27] Kuller LH, Ockene J, Meilahn E, Svendsen KH. Relation of forced expiratory volume in one second (FEV1) to lung cancer mortality in the Multiple Risk Factor Intervention Trial (MRFIT). Am J Epidemiol. 1990; 132(2):265-274.

[28] Van den Eeden SK, Friedman GD. Forced expiratory volume (1 second) and lung cancer incidence and mortality. Epidemiology. 1992; 3(3):253257.

[29] Bolton JWR, Weiman DS, Haynes JL, Hornung CA, Olsen GN, Almond $\mathrm{CH}$. Stair climbing as an indicator of pulmonary function. Chest. 1987; 92(5):783-788.

[30] Divo M, Cote C, de Torres JP, Casanova C, Marin JM, et al. Comorbidities and risk of mortality in patients with chronic obstructive pulmonary disease. Am J Respir Crit Care Med. 2012; 186(2):155-161.

[31] Brody JS, Spira A. State of the art. Chronic obstructive pulmonary disease, inflammation, and lung cancer. Proc Am Thorac Soc. 2006; 3(6):535-537.

[32] Olsen GN, Bolton JWR, Weiman DS, Hornung CA. Stair climbing as an exercise test to predict the postoperative complications of lung resection: two years' experience. Chest. 1991; 99(3):587-590. 